Article

\title{
A Pathway to Reduce Energy Consumption in the Thermal Stabilization Process of Carbon Fiber Production
}

\author{
Srinivas Nunna *, Maxime Maghe, Seyed Mousa Fakhrhoseini ${ }^{10}$, Bhargav Polisetti \\ and Minoo Naebe * \\ Institute for Frontier Materials, Carbon Nexus, Deakin University, 75 Pigdons Road, Waurn Ponds, \\ Victoria 3217, Australia; maxime.maghe@deakin.edu.au (M.M.); sfakhrho@deakin.edu.au (S.M.F.); \\ bharg@deakin.edu.au (B.P.) \\ * Correspondence: srinivas.nunna@deakin.edu.au (S.N.); minoo.naebe@deakin.edu.au (M.N.)
}

Received: 11 April 2018; Accepted: 3 May 2018; Published: 4 May 2018

\begin{abstract}
Process parameters, especially in the thermal stabilization of polyacrylonitrile (PAN) fibers, play a critical role in controlling the cost and properties of the resultant carbon fibers. This study aimed to efficiently handle the energy expense areas during carbon fiber manufacturing without reducing the quality of carbon fibers. We introduced a new parameter (recirculation fan frequency) in the stabilization stage and studied its influence on the evolution of the structure and properties of fibers. Initially, the progress of the cyclization reaction in the fiber cross-sections with respect to fan frequencies $(35,45$, and $60 \mathrm{~Hz})$ during stabilization was analyzed using the Australian Synchrotron-high resolution infrared imaging technique. A parabolic trend in the evolution of cyclic structures was observed in the fiber cross-sections during the initial stages of stabilization; however, it was transformed to a uniform trend at the end of stabilization for all fan frequencies. Simultaneously, the microstructure and property variations at each stage of manufacturing were assessed. We identified nominal structural variations with respect to fan frequencies in the intermediate stages of thermal stabilization, which were reduced during the carbonization process. No statistically significant variations were observed between the tensile properties of fibers. These observations suggested that, when using a lower fan frequency $(35 \mathrm{~Hz})$, it was possible to manufacture carbon fibers with a similar performance to those produced using a higher fan frequency $(60 \mathrm{~Hz})$. As a result, this study provided an opportunity to reduce the energy consumption during carbon fiber manufacturing.
\end{abstract}

Keywords: microstructure; carbon fibers; polyacrylonitrile; thermal stabilization; recirculation fan frequency; IR imaging

\section{Introduction}

Carbon fibers play a significant role in the manufacture of lightweight composite structures for automotive, aerospace, and defense applications, mainly due to their high specific strength and high specific stiffness [1-4]. The manufacture of carbon fibers includes (1) polyacrylonitrile (PAN) fiber spinning, (2) the stabilization of PAN fibers in an air atmosphere between $200-300{ }^{\circ} \mathrm{C}$, (3) the low temperature carbonization of stabilized fibers in an inert atmosphere from $450-1000{ }^{\circ} \mathrm{C}$, and (4) the high temperature carbonization of fibers in an inert atmosphere up to $1600{ }^{\circ} \mathrm{C}$ or above [5-8]. Out of these steps, stabilization is considered to be the most time- and energy-consuming step, as it consumes almost $48 \%$ of energy during PAN to carbon fiber conversion $[7,9,10]$. It is accepted that along with precursor fiber quality, the stabilization of precursor fibers is critical in defining the carbon 
fiber properties [11]. The thermal stabilization process is an exothermic process in which the linear polymer structure in the precursor fibers transforms to the ladder structure [12,13], which is essential to withstand high temperatures during the carbonization process [14].

This process is predominantly controlled by three parameters; temperature, time, and fiber tension [15]. From an industrial perspective, recirculation air fan frequency is another parameter that plays a substantial role in the stabilization stage as it helps to precisely maintain the oven set temperatures by the recirculation of heated air at a targeted velocity. Also it provides a fresh mixture of air to fibers and helps to remove exothermic heat from the fibers through gentle filament shaking [16] (Figure 1). Not only does it help to control the process, it also contributes to the energy consumption, hence a deeper understanding of its influence on the resultant carbon fiber properties would be beneficial to identify ways to reduce the energy consumption in carbon fiber manufacturing. In the past, Dunham et al. [17] validated the importance of air velocity in the stabilization oven in order to maintain adequate heat transfer conditions to avoid fiber degradation. However, this study was confined to a conceptual approach rather than identifying its influence on the structure and properties of fibers during carbon fiber manufacturing. To the best of our knowledge, it is the only study that showed the importance of air flow velocity in the stabilization of PAN fibers. On the other hand, it is essential to understand its role in controlling the progress of the exothermic reaction in the fiber cross-sections during thermal stabilization before any informed decisions are made. As was demonstrated earlier, the dissipation of extra heat from the fiber during thermal treatment plays a critical role in establishing homogeneous radial structure [18].

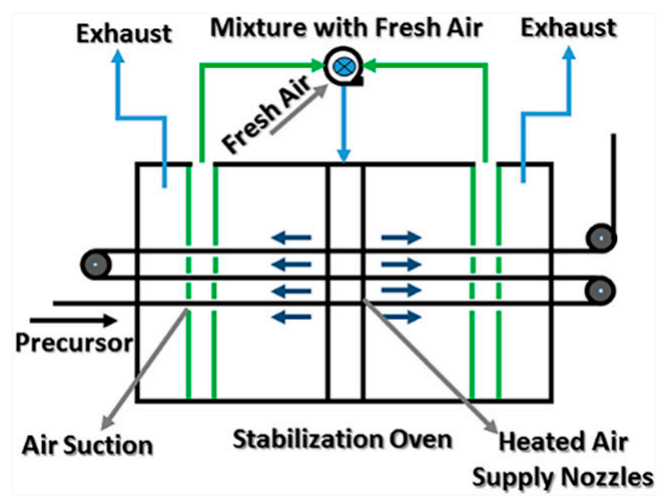

Figure 1. Schematic representation of a stabilization oven with air flow from the center to ends.

Hence, in the current study we sought to understand the influence of recirculation fan frequency on the development of the structure and properties of stabilized fibers and subsequent carbon fibers manufactured under industrial standards. Samples were obtained by processing fibers using a continuous process research line, equipped with center-to-ends ovens, by considering three recirculation fan frequencies in the stabilization ovens. Initially, the chemical structure evolution was assessed with Australian Synchrotron-high resolution IR micro-spectroscopy on the fiber cross-sections. Later, the development of microstructure and variation of properties at each stage of the carbon fiber manufacturing process were studied with respect to fan frequencies. Finally, suggestions were given in order to reduce the energy consumption during carbon fiber manufacturing without losing the quality of the final carbon fibers.

\section{Experimental}

\subsection{Sample Preparation}

PAN fibers (24 k tow) with an average diameter of $\sim 12.9 \pm 0.89 \mu \mathrm{m}$ were acquired from BlueStar co Ltd., Beijing, China, and were used for carbon fiber processing using a research scale line (see schematic 
in Figure 2), located at Carbon Nexus, Australia. Three sets of samples were prepared by varying only the recirculation fan frequencies in the stabilization ovens, as shown in Table 1. In order to maintain uniform temperatures throughout the stabilization oven, a minimum fan frequency is required. Based on our initial work, we identified that a minimum of $35 \mathrm{~Hz}$ was required for the considered oven volume to maintain acceptable conditions for thermal stabilization. Moreover, the maximum fan frequency was considered to be $60 \mathrm{~Hz}$ in order to avoid any physical damage to fibers due to violent vibrations at higher air flow velocities. The air flow velocity inside the oven at various fan speeds were measured at $50{ }^{\circ} \mathrm{C}$ by placing an Anemometer (testo 435) approximately $20 \mathrm{~cm}$ downstream from the central supply nozzle on either side (see Figure 1). The air velocities were registered as $2.01 \pm 0.09,2.97 \pm 0.04$, and $4.05 \pm 0.05 \mathrm{~m} / \mathrm{s}$ for fan frequencies $35 \mathrm{~Hz}, 45 \mathrm{~Hz}$, and $60 \mathrm{~Hz}$, respectively. Samples were collected at the end of each zone of stabilization, and at the output of the low temperature (LT) and high temperature (HT) carbonization stages.

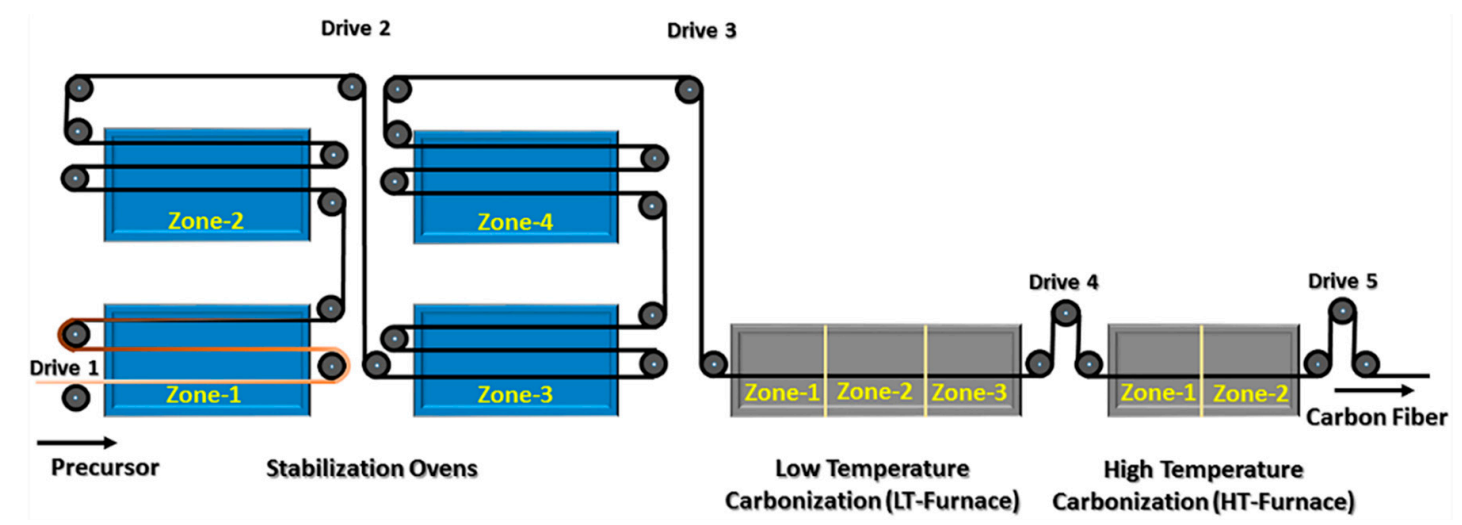

Figure 2. Schematic representation of the research production line at Carbon Nexus.

Table 1. Process parameters used for sample preparation.

\begin{tabular}{cccccccc}
\hline \multirow{2}{*}{ Stage } & Position & \multicolumn{3}{c}{ Constant Process Parameters } & \multicolumn{3}{c}{ Variable Process Parameter } \\
\cline { 3 - 8 } & & $\begin{array}{c}\text { Temperature } \\
\left({ }^{\circ} \mathbf{C}\right)\end{array}$ & $\begin{array}{c}\text { Time } \\
\text { (Min) }\end{array}$ & $\begin{array}{c}\text { Tension } \\
(\mathbf{c N})\end{array}$ & $\begin{array}{c}\text { Recirculation Fan } \\
\text { Frequency (Hz)-1 }\end{array}$ & $\begin{array}{c}\text { Recirculation Fan } \\
\text { Frequency (Hz)-2 }\end{array}$ & $\begin{array}{c}\text { Recirculation Fan } \\
\text { Frequency (Hz)-3 }\end{array}$ \\
\hline Stabilization & Zone-1 & 227 & 20 & $2650 \pm 50$ & 35 & 45 & 60 \\
& Zone-2 & 237 & 20 & $2650 \pm 50$ & 35 & 45 & 60 \\
& Zone-3 & 248 & 20 & $2850 \pm 250$ & 35 & 45 & 60 \\
Zone-4 & 258 & 20 & $2850 \pm 250$ & 35 & & \\
$\begin{array}{c}\text { Low Temperature } \\
\text { (LT) }\end{array}$ & Zone-3 & $\sim 850$ & $\sim 6$ & $\sim 2000$ & & \\
$\begin{array}{c}\text { High Temperature } \\
\text { (HT) }\end{array}$ & Zone-2 & $\sim 1400$ & $\sim 4$ & $\sim 3200$ & & & \\
\hline
\end{tabular}

\subsection{X-ray Diffraction Studies}

Wide angle X-ray diffraction studies were conducted on fiber samples using an X-pert pro XRD machine, PANalytical, equipped with a $\mathrm{Cu}-\mathrm{K} \alpha$ radiation source (wave length of $\mathrm{X}$-rays $\lambda=1.5406 \AA$, operating conditions $40 \mathrm{kV}$ and $30 \mathrm{~mA}$ ). The apparent crystallite size and d-spacing of the samples were obtained using Equations (1) and (2) [19].

$$
\begin{aligned}
L_{c} & =\frac{K \lambda}{B \cos \theta} \\
n \lambda & =2 d \sin \theta
\end{aligned}
$$

\subsection{Tensile Testing}

The single filament tensile testing was conducted by Textechno Favimat, which was mounted with a load cell of $210 \mathrm{cN}$. A gauge length of $25 \mathrm{~mm}$ and a pretension of $0.5 \mathrm{cN}$ were considered for 
the tests. For testing precursor and stabilized fibers a speed of $12.5 \mathrm{~mm} / \mathrm{min}$ was used, whereas for carbon fibers $2 \mathrm{~mm} / \mathrm{min}$ was used. At least 50 filaments were tested for each sample.

\subsection{IR Studies}

IR imaging on the fiber cross-sections was performed in Attenuated Total Reflectance (ATR) mode at the infrared micro-spectroscopy beam line, Australian Synchrotron. Initially, the samples were mounted in epoxy blocks and polished up to $1-\mu \mathrm{m}$ precision before proceeding with imaging. The samples were brought to focus using $20 \times$ objective lens and areas of measurement were selected. This is followed by bringing the Ge crystal in to focus the measurement of the background in air at a resolution of $4 \mathrm{~cm}^{-1}$ and 128 co-added scans. After background measurement, samples were brought into contact with the crystal for the spectral acquisition from the selected area. The spot size considered for acquiring IR spectra was $3.1 \mu \mathrm{m}$, and the selected area was scanned at a step size of $1 \mu \mathrm{m}$. IR spectra at each spot were collected between 700 and $3800 \mathrm{~cm}^{-1}$ wavenumbers at a resolution of $4 \mathrm{~cm}^{-1}$. Each spectrum is a representation of 32 co-added scans. The acquired data was post-processed and baseline corrected using OPUS software. Since the resolution is high, we were not able to achieve a decent signal-to-noise ratio for wavenumbers below $1200 \mathrm{~cm}^{-1}$. Based on the absorbance intensity corresponding to nitrile and $\mathrm{C}=\mathrm{N}$ functional groups, the cyclization index was calculated using Equation (3) [18].

$$
\text { Cyclization index }=\frac{0.29 \times A b s(1584)}{(A b s(2243)+0.29 \times A b s(1584))}
$$

\section{Results and Discussion}

\subsection{Chemical Structure Transformation during Thermal Stabilization}

The thermal stabilization of PAN fibers involves three major reactions: cyclization, dehydrogenation, and oxidation [20]. Out of these reactions, it is well known that cyclization is an exothermic reaction [21]. During thermal stabilization any imbalance between the process parameters could lead to an uncontrolled exothermic reaction that results in the rapid degradation of fibers. Moreover, it has been determined that the cyclization reaction plays a critical role in the formation of radial heterogeneity in fibers $[18,22]$. The cyclization reaction is associated with the conversion of $\mathrm{C} \equiv \mathrm{N}$ to $\mathrm{C}=\mathrm{N}$ [21]. The variation of these functional groups in the fiber cross-section with respect to fan frequencies assists in the understanding of the influence of heat transfer conditions inside the oven in controlling the progress of the cyclization reaction and the evolution of the cross-sectional structure. Figure 3 shows $\mathrm{C} \equiv \mathrm{N}$ and $\mathrm{C}=\mathrm{N}$ functional group distribution in the fiber cross-sections. The blue regions shown in Figure 3 are associated with epoxy and the green region represents the transition region from epoxy to fibers. In the current study, only the central regions of fibers were considered for further analysis. Overall, Figure 3 shows that the $\mathrm{C} \equiv \mathrm{N}$ functional groups are uniformly distributed in PAN and thermally stabilized fibers. Moreover, no clear distinction in the distribution of $\mathrm{C}=\mathrm{N}$ in the fiber cross-sections is observed in Zone- 4 samples irrespective of the fan frequency, as shown in Figure 3 (right-hand side). This homogenous distribution could indicate the end of the thermal stabilization stage, where most of the nitrile groups are transformed to $\mathrm{C}=\mathrm{N}$.

It is also evident that there are some fibers which showed a higher absorbance intensity of the respective functional groups compared to others, indicating the heterogeneity in the progress of reaction between the fibers. However, relative variation in the measurement of these two functional groups at various stages of thermal stabilization could potentially assist in reducing the effects of surface unevenness in the fiber cross-sections and provides clear evidence of the progress of cyclization at each stage with respect to the fan frequencies. 


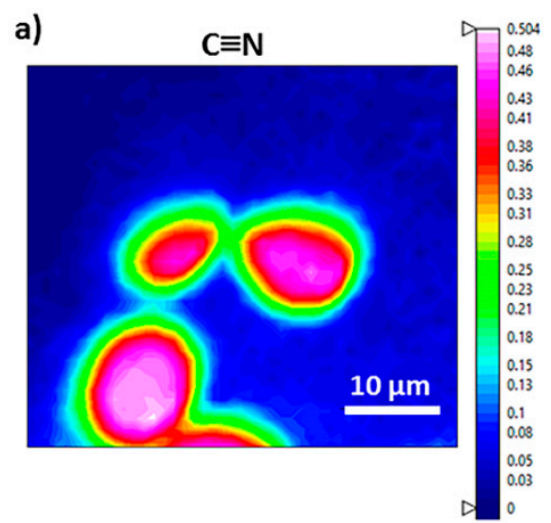

b)
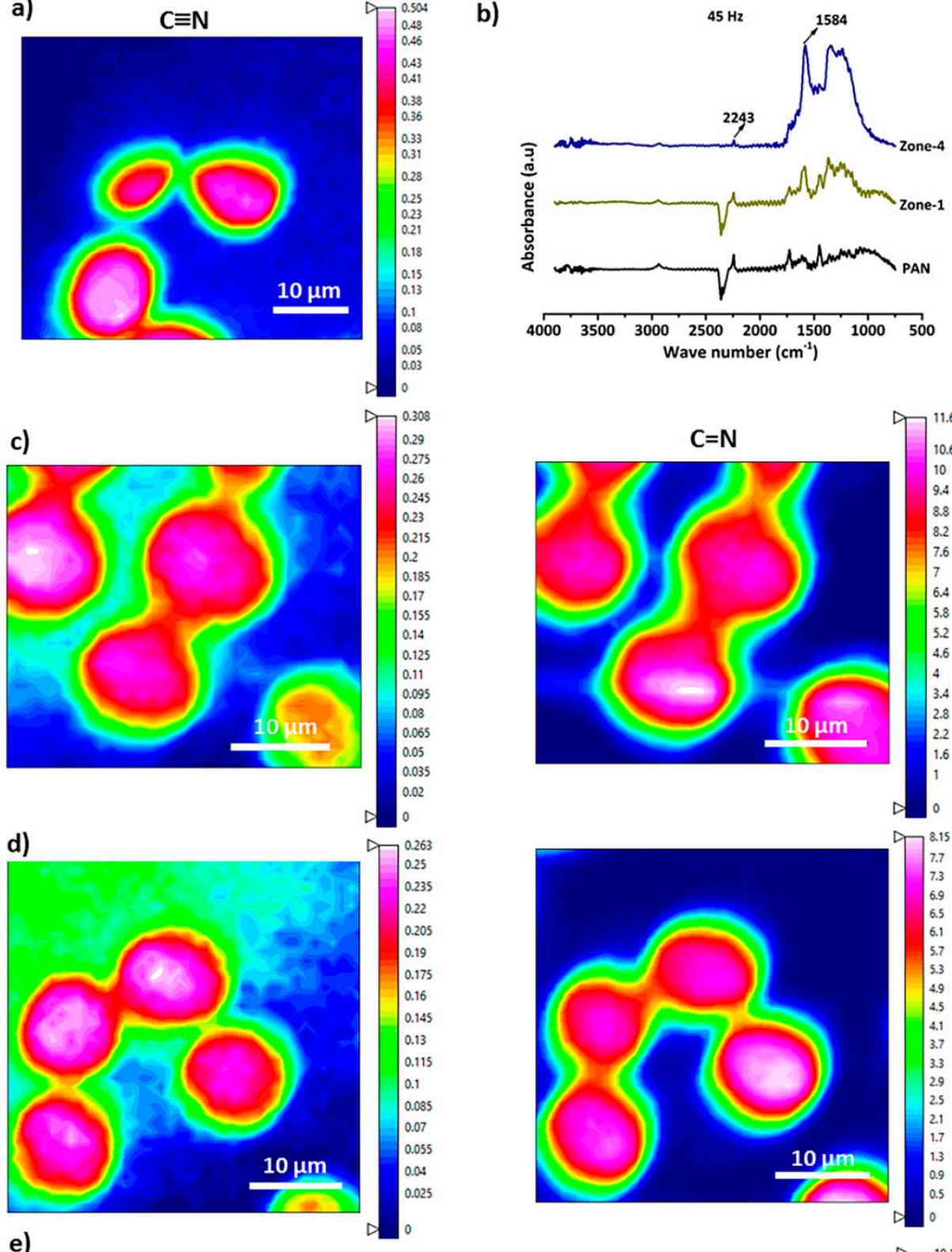

e)

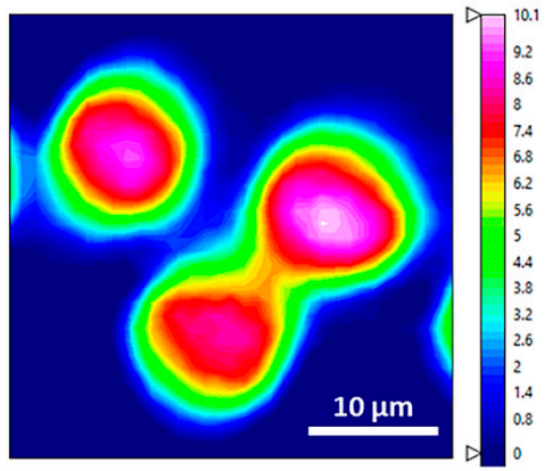

Figure 3. Distribution of nitrile $(C \equiv N)$ and $C=N$ functional groups in the fiber cross-sections of PAN and Zone-4 samples with respect to fan frequencies. (a) PAN, (b) FTIR spectra, (c) $35 \mathrm{~Hz}$, (d) $45 \mathrm{~Hz}$, and (e) $60 \mathrm{~Hz}$. (Note: the left column indicates $\mathrm{C} \equiv \mathrm{N}$ distribution and the right column indicates $\mathrm{C}=\mathrm{N}$ distribution in thermally treated fibers). 
In Figure $3 b$, absorbance peaks at wavenumbers 2243 and $1584 \mathrm{~cm}^{-1}$ correspond to $\mathrm{C} \equiv \mathrm{N}$ and a combination of $\mathrm{C}=\mathrm{N}, \mathrm{C}=\mathrm{C}$, and $\mathrm{N}-\mathrm{H}$ functional groups [23]. There is an overall decrease in the absorbance intensity of peak at $2243 \mathrm{~cm}^{-1}$ and an increase in the intensity of peak at $1584 \mathrm{~cm}^{-1}$ from PAN to the final stabilization stage (Zone-4) samples, representing the progress of the cyclization reaction. Also, each spectrum was extracted from measured positions across the fiber diameter and assessed to understand the progress of the cyclization reaction in the fiber cross-sections with respect to the fan frequencies in early stage (Zone-1) and final stage (Zone-4) samples. The relative variation in these functional groups at each position in the fiber diameter is represented quantitatively in Figure 4 using Equation (3). Interestingly, fibers in Zone-1 showed a parabolic trend in the cyclization index across the fiber cross-sections irrespective of the fan frequency used, indicating that the progress of cyclization is higher in the central region compared to the surface regions of the fiber. On the surface region of fibers, the extra heat generated by the exothermic reaction is dissipated by means of heat exchange with the surrounding air. However, in the central region of fibers there is no route for the heat dissipation, which further triggers the progress of cyclization [22,24]. Moreover, this heterogeneity in the progress of cyclization in the fiber cross-section is diminished at the end of Zone-4 for all samples, which supports our previous claim that most nitriles are converted to $\mathrm{C}=\mathrm{N}$ by this stage. In addition, no statistically significant difference in the cyclization index of samples treated at various fan frequencies is observed (Figure 4). Overall, it can be deduced that the lowest fan frequency $(35 \mathrm{~Hz})$ is sufficient to sustain the heat transfer conditions inside the oven.

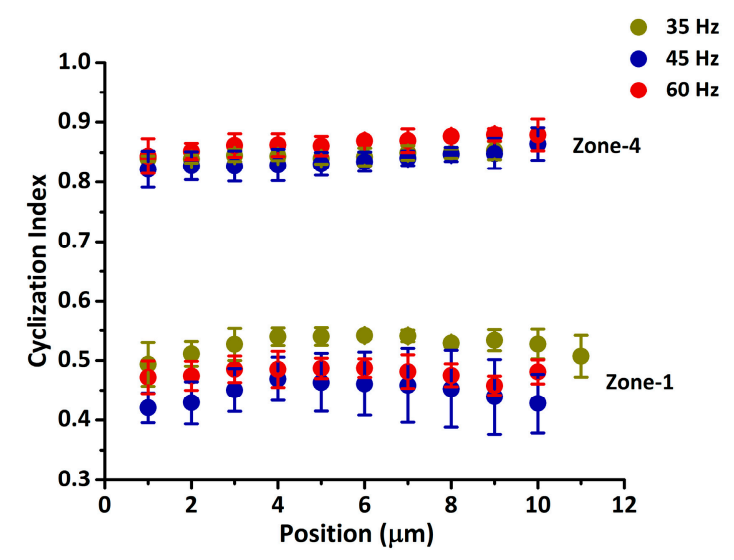

Figure 4. Cyclization index variation across the fiber cross-section in thermal stabilization.

\subsection{Microstructure and Property Variation in Fibers}

In the diffraction graphs shown in Figure 5a,b, three peaks were observed and located at $\sim 17^{\circ}$, which was associated with crystal plane $(100)[25,26]$, at $\sim 26^{\circ}$, related to crystallographic plane (002), and at $\sim 29.5^{\circ}$, assigned to crystal plane $(110)[25,27,28]$. In PAN fibers a small hump at $\sim 26^{\circ}$ appeared to be associated with some weak systematically arranged units in the amorphous regions. The apparent crystallite size associated with the peaks at $17^{\circ}$ and $26^{\circ}$ was calculated using Equation (1). From Figure $5 c$, a sharp increase in crystallite size was observed for Zone-1 fibers compared to PAN fibers for all fan frequencies. However, from Zone-2, fibers experienced a gradual decrease in crystallite size. Simultaneously, a sharp decrease in apparent crystallite size associated with the partial systematic units in the amorphous regions (Figure 5d) was perceived for all fibers until Zone-2 of the stabilization process in comparison with PAN fibers (i.e., from $\sim 2.15 \mathrm{~nm}$ to $1.22 \mathrm{~nm}(35 \mathrm{~Hz}), 1.07 \mathrm{~nm}$ $(45 \mathrm{~Hz})$, and $1.49 \mathrm{~nm}(60 \mathrm{~Hz}))$. This was followed by a gradual increase in the apparent crystallite size associated with crystallographic plane (002) to $\sim 1.9 \mathrm{~nm}$ in carbon fibers irrespective of the fan frequency used during thermal stabilization. 


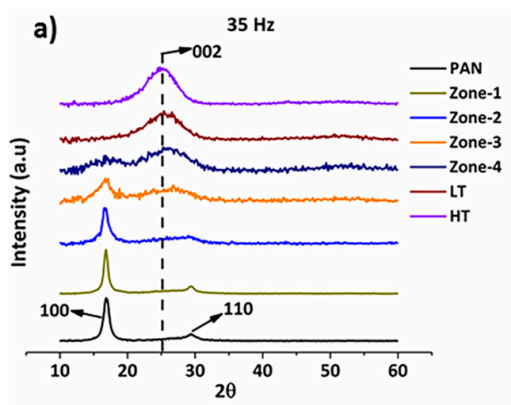

d)

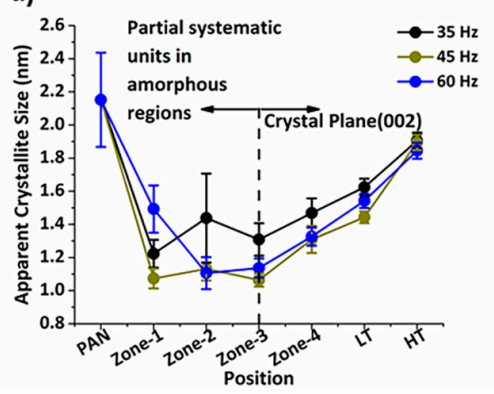

b)

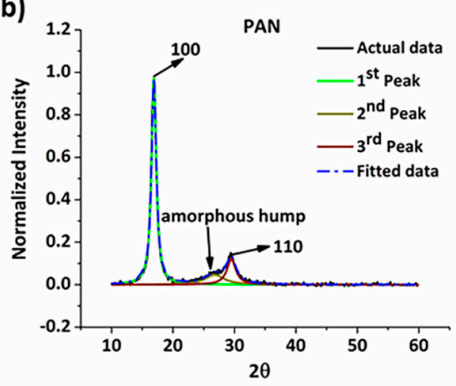

c)

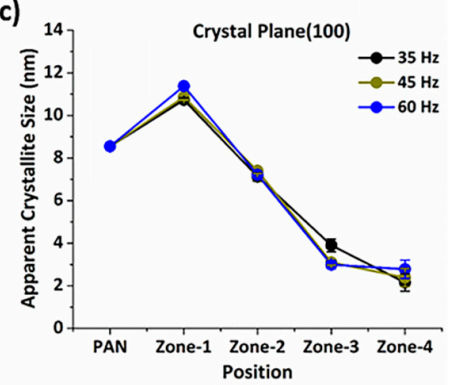

e)

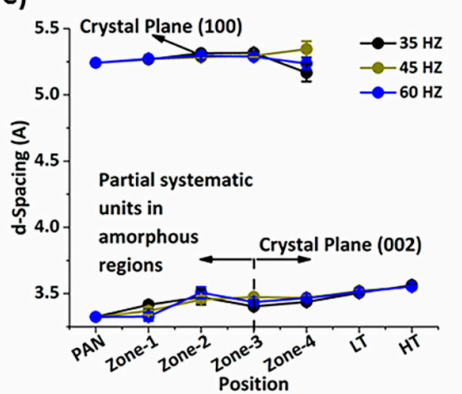

Figure 5. (a) X-ray diffraction peaks of fibers, (b) Lorentz curve fitting of PAN fibers, (c) apparent crystallite size variation in stabilization stage, $(\mathbf{d})$ apparent crystallite size variation throughout the carbon fiber manufacturing, (e) d-spacing trends corresponding to crystal planes (100) and (002).

Initially, the functional groups of amorphous regions are more easily involved in stabilization reactions compared to highly crystalline regions [28,29]. During these procedures, some of the molecular chains in the amorphous phase arranged themselves into crystalline regions induced by improved dipole interactions between nitrile groups, assisted by segmental mobility [28,29]. This phenomenon helped in the crystallite growth. In support of this proposal, a sharp increase in crystallite size (Figure 5c) coupled with a decrease in the size of systematically arranged units from the amorphous regions (Figure $5 \mathrm{~d}$ ) was noticed in fibers from Zone- 1 compared to PAN fibers. However, at higher temperatures, the energy was sufficient enough to initiate the stabilization reactions in the crystalline regions, which further ruptured the molecular rod structure and thereby reduced the crystallite size (Figure 5c) [28,29].

An evolution of turbostratic graphitic structure associated with crystallographic plane (002) (Figure 5d) was also discerned from Zone-3 to HT. This was developed by the rupture of crystallites in PAN fibers during thermal stabilization and the simultaneous progress of intermolecular crosslinking and removal of heteroatoms in the polymer [25]. Although there was a difference in the apparent crystallite size between fibers treated at different fan frequencies from Zone-2, these differences steadily decreased with the progress of thermal treatment.

In addition, the d-spacing of the crystallites was calculated using Equation (2). From Figure 5e, with the progress of thermal treatment, crystallites associated with (100) displayed an increase in planar spacing from $\sim 5.24$ to $5.34 \AA$. Similar to this trend, the partial systematics units and crystallites related to (002) showed an increment in the d-spacing from $\sim 3.32$ to $\sim 3.5 \AA$ and from $\sim 3.4$ to $3.56 \AA$. In case of crystallites corresponded to (100) and partial ordered units in the amorphous region, the progress of stabilization reactions from the ends of the molecular rods and in the amorphous regions might have led to a gradual increase in d-spacing, whereas in case of crystallites related to (002) after Zone-3, a steady increase in crosslinking atoms between the layers of a planar structure could be the reason for a gradual increase in the d-spacing. Moreover, unlike crystallite size, the d-spacing trends demonstrated no significant differences with respect to the recirculation fan frequencies in the intermediate stages of carbon fiber manufacturing. 
Supporting the structural data, no significant difference in the fiber properties were observed, as shown in Figure 6. Overall, the percentage elongation of fibers increased with thermal stabilization (Figure 6a), while decreasing trends were observed in strength and modulus (Figure 6b,c). The loss of the tensile strength of fibers was attributed to the reduction of cohesive energy in the molecular chains with the progress of the cyclization reaction in the fiber structure [30]. Interestingly, the trend of tensile modulus (Figure 6c) was similar to the apparent crystallite size trend shown in Figure 5c, supporting the argument related to the improvement of morphological order at the initial stages. From Figure $6 \mathrm{~d}, \mathrm{f}$, after carbonization, an overall rapid decrease in the \% elongation of fibers and a rapid increase in the tensile strength and modulus of fibers was observed compared to stabilized fibers. This was attributed to an improvement in the growth of the planar carbon network with the promotion of intermolecular crosslinking and an increase in the stacking size $\left(L_{c}\right)$ and its orientation. Given the observations, it can be concluded that the stimulation of fiber tow at the lowest fan frequency during thermal stabilization should be sufficient enough to dissipate the exothermic heat from the considered fiber tow size. Moreover, considering the volume of the oven, the amount of extra heat generated by the stabilization reactions from a single tow might not be sufficient enough to create noticeable changes in the reaction front. However, the influence of varying the tow size on the generation of local exothermic heat inside the tow with respect to various fan frequencies during thermal stabilization needs to be further analyzed; this work is under progress. Moreover, in the future we will work on identifying the balance between air flow conditions and treatment temperature in order to reduce the residence time in stabilization without reducing the quality of the carbon fibers.

a)

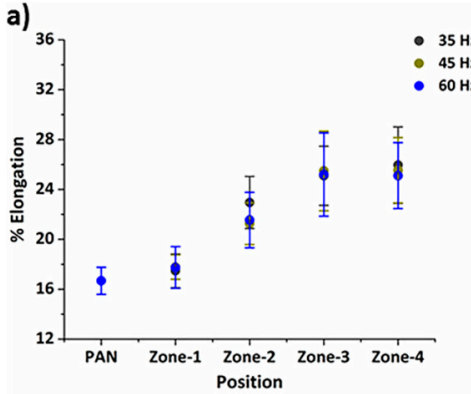

d)

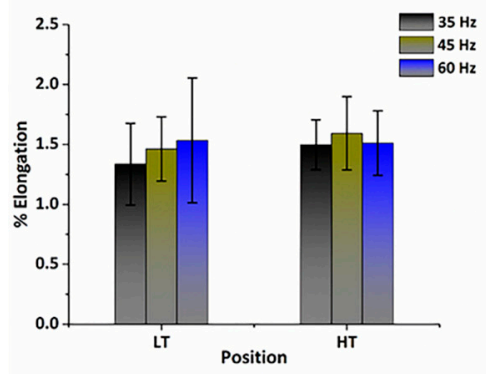

b)

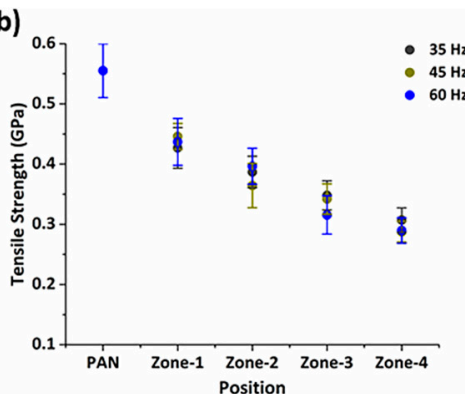

e)

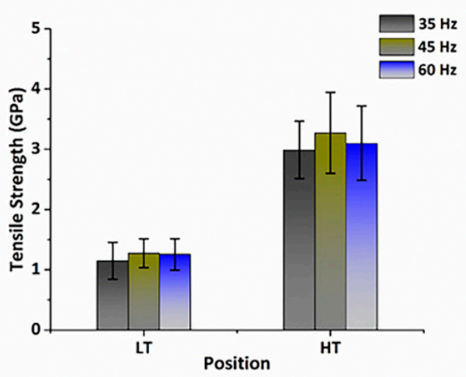

c)

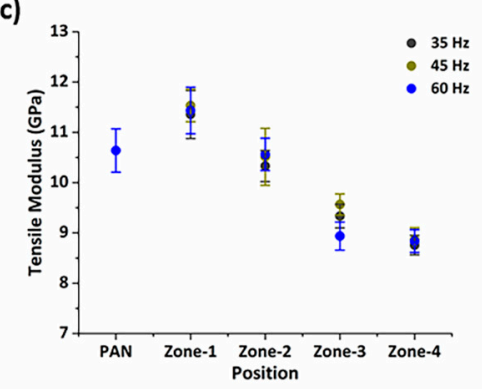

f)

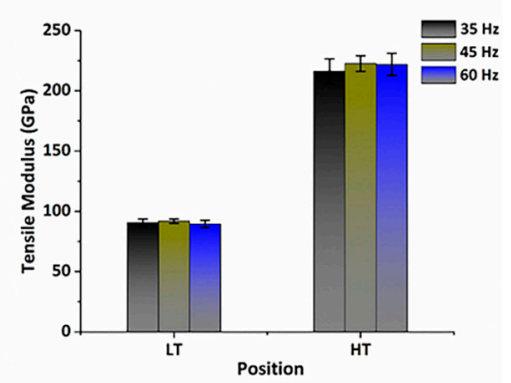

Figure 6. Tensile properties of stabilized and carbon fibers (LT and HT) with respect to recirculation fan frequencies with the (a) \% elongation at break, (b) tensile strength, (c) tensile modulus of stabilized fibers, and the (d) \% elongation at break, (e) tensile strength, and (f) tensile modulus of carbon fibers extracted from LT and HT furnaces.

\section{Conclusions}

The influence of recirculation fan frequency on the structure and property variations in fibers during thermal stabilization as well as the resultant carbon fibers was systematically examined. Overall analysis showed that no significant differences were observed in terms of structure or properties of stabilized and carbonized fibers for the chosen recirculation fan frequencies. The possible reason for this could be that the stimulation of fiber tow at the lowest fan frequency during thermal stabilization 
was sufficient enough to dissipate the exothermic heat from the fiber tow while allowing adequate stabilization conditions for fibers. Hence, it may be possible to use lower recirculation fan frequencies (e.g., $35 \mathrm{~Hz}$ ) during thermal stabilization to manufacture carbon fibers with similar properties to those produced using a higher fan frequency (e.g., $60 \mathrm{~Hz}$ ). This study shows a possible path towards potential approaches to the reduce energy consumption of carbon fiber production and develop a low cost carbon fiber, which is of high importance for automotive lightweight structural applications.

Author Contributions: S.N. and M.N. conceived and designed the experiments, conducted major analysis, wrote the paper; S.N. and M.M. performed IR imaging at Australian synchrotron; M.M. and B.P. worked on sample preparation and performed initial analysis; S.M.F. performed X-ray diffraction analysis on the samples.

Acknowledgments: This research was supported by the Australian Research Council World Class Future Fiber Industry Transformation Research Hub (IH140100018) and the Australian Research Council Training Center for Lightweight Automotive Structures (ATLAS). We also thank the Carbon Nexus operational team for the manufacture of fibers. We are thankful to Australian Synchrotron for providing access to the IRM beamline for fiber characterization.

Conflicts of Interest: The authors declare no conflicts of interest.

\section{References}

1. Jasjeet, K.; Keith, M.; Shaun, S. Producing high-quality precursor polymer and fibers to achieve theoretical strength in carbon fibers: A review. J. Appl. Polym. Sci. 2016, 133, 43963.

2. Liu, J.; Yue, Z.; Fong, H. Continuous nanoscale carbon fibers with superior mechanical strength. Small 2009, 5, 536-542. [CrossRef] [PubMed]

3. Zhao, W.; Lu, Y.; Zhou, L.; Jiang, J.; Wang, J.; Chen, Q.; Tian, F. Effects on the oriented structure and mechanical properties of carbon fibers by pre-irradiating polyacrylonitrile fibers with $\gamma$ ray. J. Mater. Sci. 2016, 51, 7073-7084. [CrossRef]

4. De Santis, V.; Campi, T.; Cruciani, S.; Laakso, I.; Feliziani, M. Assessment of the induced electric fields in a carbon-fiber electrical vehicle equipped with a wireless power transfer system. Energies 2018, 11, 684. [CrossRef]

5. Ko, T.H. The influence of pyrolysis on physical properties and microstructure of modified PAN fibers during carbonization. J. Appl. Polym. Sci. 1991, 43, 589-600. [CrossRef]

6. Nunna, S.; Naebe, M.; Hameed, N.; Fox, B.L.; Creighton, C. Evolution of radial heterogeneity in polyacrylonitrile fibres during thermal stabilization: An overview. Polym. Degrad. Stab. 2017, 136, 20-30. [CrossRef]

7. Maghe, M.; Creighton, C.; Henderson, L.C.; Huson, M.G.; Nunna, S.; Atkiss, S.; Byrne, N.; Fox, B.L. Using ionic liquids to reduce energy consumption for carbon fibre production. J. Mater. Chem. A 2016, 4, 16619-16626. [CrossRef]

8. Khayyam, H.; Naebe, M.; Bab-Hadiashar, A.; Jamshidi, F.; Li, Q.; Atkiss, S.; Buckmaster, D.; Fox, B. Stochastic optimization models for energy management in carbonization process of carbon fiber production. Appl. Energy 2015, 158, 643-655. [CrossRef]

9. Golkarnarenji, G.; Naebe, M.; Badii, K.; Milani, A.S.; Jazar, R.N.; Khayyam, H. Production of Low Cost Carbon-Fiber through Energy Optimization of Stabilization Process. Materials 2018, 11, 385. [CrossRef] [PubMed]

10. Golkarnarenji, G.; Naebe, M.; Badii, K.; Milani, A.S.; Jazar, R.N.; Khayyam, H. Support vector regression modelling and optimization of energy consumption in carbon fiber production line. Comp. Chem. Eng. 2018, 109, 276-288. [CrossRef]

11. Ko, T.H.; Li, C.H.; Hu, C.H. The characterization of high-performance PAN-based carbon fibers developed by continuous carbonization and air oxidation. J. Mater. Res. 1995, 10, 1529-1538. [CrossRef]

12. Fitzer, E.; Frohs, W.; Heine, M. Optimization of stabilization and carbonization treatment of PAN fibres and structural characterization of the resulting carbon fibres. Carbon 1986, 24, 387-395. [CrossRef]

13. Khayyam, H.; Fakhrhoseini, S.M.; Church, J.S.; Milani, A.S.; Bab-Hadiashar, A.; Jazar, R.N.; Naebe, M. Predictive modelling and optimization of carbon fiber mechanical properties through high temperature furnace. Appl. Therm. Eng. 2017, 125, 1539-1554. [CrossRef] 
14. Wang, L.; Lu, W.; Zhang, L.; Xue, L.; Ryu, S.K.; Jin, R.G. Effects of positive and negative stretching on the structure and properties of polyacrylonitrile fibers in the pre-oxidation process. Carbon Lett. 2011, 12, 107-111. [CrossRef]

15. Nunna, S.; Naebe, M.; Hameed, N.; Creighton, C.; Naghashian, S.; Jennings, M.J.; Atkiss, S.; Setty, M.; Fox, B.L. Investigation of progress of reactions and evolution of radial heterogeneity in the initial stage of thermal stabilization of PAN precursor fibres. Polym. Degrad. Stab. 2016, 125, 105-114. [CrossRef]

16. Badii, K.; Naebe, M.; Golkarnarenji, G.; Dhami, N.; Atkiss, S.; Buckmaster, D.; Fox, B.; Khayyam, H. Energy Saving in Electric Heater of Carbon Fiber Stabilization Oven. In Proceedings of the 2014 4th International Conference on Artificial Intelligence with Applications in Engineering and Technology (ICAIET), Kota Kinabalu, Malaysia, 3-5 December 2014; pp. 109-114.

17. Dunham, M.G.; Edie, D.D. Model of stabilization for pan-based carbon fiber precursor bundles. Carbon 1992, 30, 435-450. [CrossRef]

18. Nunna, S.; Creighton, C.; Fox, B.L.; Naebe, M.; Maghe, M.; Tobin, M.J.; Bambery, K.; Vongsvivut, J.; Hameed, $\mathrm{N}$. The effect of thermally induced chemical transformations on the structure and properties of carbon fibre precursors. J. Mater. Chem. A 2017, 5, 7372-7382. [CrossRef]

19. Liu, F.; Wang, H.; Xue, L.; Fan, L.; Zhu, Z. Effect of microstructure on the mechanical properties of PAN-based carbon fibers during high-temperature graphitization. J. Mater. Sci. 2008, 43, 4316-4322. [CrossRef]

20. Zhao, J.; Zhang, J.; Zhou, T.; Liu, X.; Yuan, Q.; Zhang, A. New understanding on the reaction pathways of the polyacrylonitrile copolymer fiber pre-oxidation: Online tracking by two-dimensional correlation FTIR spectroscopy. RSC Adv. 2016, 6, 4397-4409. [CrossRef]

21. Khayyam, H.; Naebe, M.; Zabihi, O.; Zamani, R.; Atkiss, S.; Fox, B. Dynamic Prediction Models and Optimization of Polyacrylonitrile (PAN) Stabilization Processes for Production of Carbon Fiber. IEEE Trans. Ind. Inform. 2015, 11, 887-895. [CrossRef]

22. Layden, G.K. Retrograde core formation during oxidation of polyacrylonitrile filaments. Carbon 1972, 10, 59-63. [CrossRef]

23. Arbab, S.; Mirbaha, H.; Zeinolebadi, A.; Nourpanah, P. Indicators for evaluation of progress in thermal stabilization reactions of polyacrylonitrile fibers. J. Appl. Polym. Sci. 2014, 131, 40343. [CrossRef]

24. Kikuma, J.; Warwick, T.; Shin, H.J.; Zhang, J.; Tonner, B.P. Chemical state analysis of heat-treated polyacrylonitrile fiber using soft X-ray spectromicroscopy. J. Electron Spectrosc. Relat. Phenom. 1998, 94, 271-278. [CrossRef]

25. Hameed, N.; Sharp, J.; Nunna, S.; Creighton, C.; Magniez, K.; Jyotishkumar, P.; Salim, N.V.; Fox, B. Structural transformation of polyacrylonitrile fibers during stabilization and low temperature carbonization. Polym. Degrad. Stab. 2016, 128, 39-45. [CrossRef]

26. Yu, M.J.; Bai, Y.J.; Wang, C.G.; Xu, Y.; Guo, P.Z. A new method for the evaluation of stabilization index of polyacrylonitrile fibers. Mater. Lett. 2007, 61, 2292-2294. [CrossRef]

27. Karacan, I.; Erdoğan, G. The role of thermal stabilization on the structure and mechanical properties of polyacrylonitrile precursor fibers. Fibers Polym. 2012, 13, 855-863. [CrossRef]

28. Wang, B.; Xiao, S.; Cao, W.; Shi, X.; Xu, L. Evolution of aggregation structure of polyacrylonitrile fibers in the cyclization reaction. J. Appl. Polym. Sci. 2012, 124, 3413-3418. [CrossRef]

29. Ko, T.H.; Lin, C.H.; Ting, H.Y. Structural changes and molecular motion of polyacrylonitrile fibers during pyrolysis. J. Appl. Polym. Sci. 1989, 37, 553-566. [CrossRef]

30. Gupta, A.; Harrison, I.R. New aspects in the oxidative stabilization of PAN-based carbon fibers: II. Carbon 1997, 35, 809-818. [CrossRef]

(C) 2018 by the authors. Licensee MDPI, Basel, Switzerland. This article is an open access article distributed under the terms and conditions of the Creative Commons Attribution (CC BY) license (http:/ / creativecommons.org/licenses/by/4.0/). 